\title{
man \\ Long Spiky Au-Ag Nanostar Based Fiber Probe for Surface Enhanced Raman Spectroscopy
}

\author{
Guangyuan He ${ }^{1}$, Xiaoyu Han ${ }^{1}$, Shiyi Cao ${ }^{1,2}$, Kaimin Cui ${ }^{1,3}$, Qihang Tian ${ }^{1}$ and Jihong Zhang $1, *$ (i) \\ 1 State Key Laboratory of Silicate Materials for Architectures, Wuhan University of Technology, \\ 122 Luoshi Road, Wuhan 430070, China; heguangyuan@whut.edu.cn (G.H.); hxy0613@whut.edu.cn (X.H.); \\ siyi@whut.edu.cn (S.C.); kaimin@whut.edu.cn (K.C.); tqh@whut.edu.cn (Q.T.) \\ 2 International School of Materials Science and Engineering, Wuhan University of Technology, 122 Luoshi Road, \\ Wuhan 430070, China \\ 3 School of Materials Science and Engineering, Wuhan University of Technology, 122 Luoshi Road, \\ Wuhan 430070, China \\ * Correspondence: optinfo@whut.edu.cn; Tel.: +86-27-8766-9729; Fax: +86-27-8766-9729
}

check for updates

Citation: He, G.; Han, X.; Cao, S.; Cui, K.; Tian, Q.; Zhang, J. Long Spiky Au-Ag Nanostar Based Fiber Probe for Surface Enhanced Raman Spectroscopy. Materials 2022, 15, 1498 https://doi.org/10.3390/ ma15041498

Academic Editor: Toma Stoica

Received: 18 January 2022

Accepted: 7 February 2022

Published: 17 February 2022

Publisher's Note: MDPI stays neutral with regard to jurisdictional claims in published maps and institutional affiliations.

Copyright: (C) 2022 by the authors. Licensee MDPI, Basel, Switzerland. This article is an open access article distributed under the terms and conditions of the Creative Commons Attribution (CC BY) license (https:// creativecommons.org/licenses/by/ $4.0 /)$.

\begin{abstract}
The detection performances of noble metal-based surface enhanced Raman spectroscopy (SERS) devices are determined by the compositions and geometries of the metal nanostructures, as well as the substrates. In the current study, long spiky Au-Ag alloy nanostars were synthesized, and both core diameters and spike lengths were controlled by Lauryl sulfobetaine concentrations (as the nanostructure growth skeleton). The long spiky star geometries were confirmed by transmission electron micrograph images. Elements energy dispersive spectrometer mapping confirmed that $\mathrm{Au}$ and Ag elements were inhomogeneously distributed in the nanostructures and demonstrated a higher Ag content at surface for potential better SERS performance. Selected synthesized spiky nanostars were uniformly assembled on multi-mode silica fiber for probe fabrication by silanization. The SERS performance were characterized using crystal violet (CV) and rhodamine 6G (R6G) as analyte molecules. The lowest detection limit could reach as low as $10^{-8} \mathrm{M}$, with a $6.23 \times 10^{6}$ enhancement factor, and the relationship between analyte concentrations and Raman intensities was linear for both CV and R6G, which indicated the potential qualitative and quantitative molecule detection applications. Moreover, the fiber probes also showed good reproducibility and stability in the ambient atmosphere.
\end{abstract}

Keywords: noble metal; nanostructure; glass fiber; local surface plasmon resonance

\section{Introduction}

Noble metal (such as silver, gold, platinum, copper, etc.) nanostructures have attracted much attention for their optical and electrical properties (originating from their local surface plasmon resonance (LSPR)) for various applications in recent years [1-3]. Surface enhanced Raman scattering (SERS) is one of these important applications for ultra-low or single molecular substance detection [4]. Raman scattering signal from analyte molecules can be exponentially amplified from the electric field resonance between nanostructure surface and attached analyte molecules [5,6] under laser excitation [7]. The SERS analytical method has been studied and applied for trace organic molecules detection, pollutant heavy metal ions monitoring [8], food safety [9], bio-sensing [10,11], and others.

The SERS performances are highly dependent on the components, morphologies, geometries of noble metal nanostructures, and supporting materials [12,13]. In general, special nanostructure geometries provide denser hot spots [14] and larger surface area for analyte attachment for better SERS detection behavior than regular sphere nanoparticles. Moreover, sharp tips in special structures generate a much stronger LSPR electric field than sphere nanoparticles [15], due to size and space effect, for further SERS improvement. Many kinds of nanostructures, such as nanocubes [16], nanorods [17], nanostars [18], octahedral 
nanoparticles [15], and nanocages [19] have been synthesized and their SERS behavior on planar supporting substrates have been investigated [20]. The results indicated that these nanostructures could have higher enhancement factors and reduce the detection limit to $10^{-9} \mathrm{M}$ scale for ultra-trace substance analysis [21,22]. In addition, the nanostructure components also are of great importance for SERS performance [23]. Pure Ag nanostructures showed better LSPR effect and SERS detection limit due to higher free electron density and broader UV-visible response range [24]. However, Ag nanostructures are easily oxidized, and the stability of Ag nanostructure-based SERS detection is still a critical problem to be solved [25]. The Raman signal rapidly decayed and disappeared in a short duration (such as $24 \mathrm{~h}$ in an ambient atmosphere). Au nanostructures show better stability while their LSPR effect and SERS detection performance were not as good as that from Ag under similar sizes or structures [26]. Au-Ag alloy nanostructures provide both a good LSPR effect and good stabilities, for potential SERS substrates, for ultra-trace molecules detection under different circumstances [27-29]. In addition, the spiky stars also could furtherly improve detection limit, from high LSPR induced field strength on sharp tips and large surface area for analyte attachment [30,31].

Silica glass fiber has been extensively applied for information communication mediums due to low optical loss, compact dimensions, lightweight, anti-electromagnetic interference, and environmental stability [32]. In fact, optical fiber can be used as metal nanostructures supporting materials for ultra-trace molecules SERS detection probes [23,33]. The fiber offers input and output optical channel for SERS excitation and detection, more importantly, provides special benefits including flexible, real-time, in-situ, and online spectral detection [34]. Since the excitation beam and SERS signal are confined into the fiber core region, there is a large proportion of scattering signal loss, which result in the detection limit and sensitivity of fiber probes are not as good as planar SERS detector [35]. Recent research found that the detection limit could reach as low as $10^{-9} \mathrm{M}$ for silver rod-based fiber probes using 4-aminothiophenol (4-ATP) as analyte [36-38] or $10^{-10} \mathrm{M}$ for Au-Ag alloy nanostars fiber probes using crystal violet (CV) as analyte [39,40]. Fiber structure designs, such as hollow fiber and tapered fiber, and active nanostructure optimization are potential methods for fiber probe detection improvement [23].

In the present research, long spiky Au-Ag nanostars were synthesized using the metal ions reduction method. The nanostructure geometries, and spiky branch length in particular, were controlled by Lauryl sulfobetaine (LSB) content addition. The sizes, morphologies, and element distributions of nanostructures were analyzed. The obtained long spiky nanostructures were homogeneously coated on the end tip and wall of silica fiber for probes fabrication. The SERS performance was characterized using CV and Rhodamine $6 \mathrm{G}$ as analytes. The reproducibility and stability of fiber probes were investigated as well. The results indicated that long spiky Au-Ag nanostars fiber probes could be applied for low concentration substance analysis.

\section{Materials and Methods}

\subsection{Materials}

Hydrogen tetrachlorocuprate (III) hydrate $\left(\mathrm{HAuCl}_{4} \cdot 3 \mathrm{H}_{2} \mathrm{O}, 99.9 \%\right)$, silver nitrate $\left(\mathrm{AgNO}_{3}\right.$, $99.99 \%)$, Sodium citrate $\left(\mathrm{C}_{6} \mathrm{H}_{5} \mathrm{O}_{7} \mathrm{Na}_{3}, 98 \%\right)$, L-dopa $\left(\mathrm{C}_{9} \mathrm{H}_{11} \mathrm{NO}_{4}, 99 \%\right)$, ascorbic acid $\left(\mathrm{C}_{6} \mathrm{H}_{8} \mathrm{O}_{6}, \mathrm{AA}, 99 \%\right)$, Lauryl sulfobetaine $\left(\mathrm{C}_{17} \mathrm{H}_{37} \mathrm{NO}_{3} \mathrm{~S}, \mathrm{LSB}, 99 \%\right)$, were purchased from Aladdin (Shanghai, China) and directly used for nanostructure synthesis without further purification. Triethoxy-3-aminopropylsilane $\left(\mathrm{C}_{9} \mathrm{H}_{23} \mathrm{NO}_{3} \mathrm{Si}\right.$, 3-APTES, 99\%, Aladdin) was used as a surfactant for fiber probes fabrication. Dye compounds, rhodamine 6G $\left(\mathrm{C}_{28} \mathrm{H}_{31} \mathrm{~N}_{2} \mathrm{O}_{3} \mathrm{C}\right.$, 99\%, Aladdin), crystal violet (CV) $\left(\mathrm{C}_{25} \mathrm{H}_{30} \mathrm{~N}_{3} \mathrm{Cl}\right.$, 99\%, Aladdin) were used as analytes for SERS performance characterization. Deionized (DI) water with a resistivity of $18.2 \mathrm{M} \Omega \cdot \mathrm{cm}$ produced using a Milli-Q SP ultrapure-water purification system from Nihon Millipore Ltd., Tokyo, Japan was used as a solvent for nanostructure synthesis. Multimode silica optical fibers with $62.5 \mu \mathrm{m}$ core diameter and $125 \mu \mathrm{m}$ total diameter were purchased from Yangtze Optical Fiber \& Cable Joint Stock Co. Ltd., Wuhan, China. 


\subsection{Synthesis Methods}

Long spiky Au-Ag alloy nanostars were synthesized according to Dickson Joseph's method [41]. $25 \mathrm{mM}, 50 \mathrm{mM}, 75 \mathrm{mM}$ and $100 \mathrm{mM}$ LSB solutions were prepared by dissolving $0.419,0.839,1.258$ and $1.678 \mathrm{~g} \mathrm{LSB}$, respectively, in $50 \mathrm{~mL}$ deionized water and stirred until completely dissolved. $0.5 \mathrm{~mL} 10 \mathrm{mM} \mathrm{HAuCl}_{4}$ solution and $0.05 \mathrm{~mL} \mathrm{AgNO}_{3}(20 \mathrm{mM})$ solution were added into LSB solution and well mixed by manual stirring. Then, $0.1 \mathrm{~mL}$ AA $(100 \mathrm{mM})$, and $0.05 \mathrm{M} \mathrm{NaOH}$ solution were added, while continuous magnetic stirring, until the solution turned dark. The solutions were kept at room temperature for $24 \mathrm{~h}$ for the growth of Au-Ag alloy nanostars. The solutions were centrifuged and washed using dehydrate ethanol and pure water several times to remove organic and inorganic intermediates, and then concentrated to $2 \mathrm{~mL}$ solution, for further use. Since the contents of $\mathrm{HAuCl}_{4}$ and $\mathrm{AgNO}_{3}$, as raw materials for $\mathrm{Au}$ and $\mathrm{Ag}$ alloy nanostructures, were fixed, the diameters and branch lengths were determined by LSB concentrations.

Multi-mode silica optical fibers with 62.5 core diameter and 125 cladding thickness were used for fiber probes fabrication. The fibers were soaked into $5 \mu \mathrm{L} / \mathrm{mL}$ 3-APTES aqueous solution for $30 \mathrm{~min}$ for surface silanization, then transferred into prepared $\mathrm{Au}-\mathrm{Ag}$ alloy nanostructures solution for $24 \mathrm{~h}$ for long spiky $\mathrm{Au}-\mathrm{Ag}$ alloy nanostars adsorption in order to fabricate fiber probes (Figure S1). Then, the fabricated fiber probes were dried in vacuum at room temperature.

\subsection{Materials Characterization}

The sizes distribution and morphologies of synthesized metal nanostructures were characterized using transmission electron microscopy (TEM, JEM-1400, JEOL, Japan), with an acceleration voltage of $200 \mathrm{kV}$. The absorption spectra of the nanostructures were measured using a UV-Vis-NIR spectrophotometer (Lambda 750S, Perkin Elmer, Waltham, MA, USA), ranging from $300 \mathrm{~nm}$ to $900 \mathrm{~nm}$. The crystal phase of obtained nanostructures was characterized using an X-Ray diffraction diffractometer (XRD, D8 DISCOVER, Bruker, Germany), operating at $40 \mathrm{kV}, 40 \mathrm{~mA}$, with $\mathrm{Cu} \mathrm{K}_{\alpha}$ radiation, $1.54056 \AA$, $2^{\circ} /$ min scanning speed, and $0.02^{\circ}$ step size. The high-resolution TEM images, element distributions mapping, and selected area electron diffraction were taken from another TEM (JEM-2100F, JEOL, Japan), and attached energy dispersive spectroscopy (EDS). The nanostructure distributions on fiber tip were characterized using a field-emission scanning electron microscope (FE-SEM, S-4800, Hitachi, Japan), images were taken using a microscope with a $5 \mathrm{kV}$ accelerating voltage. The digital images of naked fiber and coated fiber were taken using an optical microscope (CX33, Olympus, Japan). All of the measurements were conducted at room temperature.

\subsection{Electromagnetic Filed Distribution Simulation}

The electromagnetic filed distributions around nanostructures were simulated using finite-difference time-domain (FDTD) analysis. The 3D models of the nanostructures were constructed following the TEM images, with individual nanostar, colliding tip-top and intercrossed naonstars, as shown in Figure S2. The excitation wavelength was $633 \mathrm{~nm}$, as the Raman measurement. The air suspension geometrical model $n_{0}=1$. The mesh range resolution was set as $1 \mathrm{~nm} \times 1 \mathrm{~nm} \times 1 \mathrm{~nm}$, the monitor position was set as $z$-axis plane, the range was set as $1 \mu \mathrm{m} \times 1 \mu \mathrm{m}$, the incident light wave vector $\mathrm{K}$ was along $z$-axis, the electric field $\mathrm{E}$ was along $X$-axis, and $\mathrm{E} 0=1 \mathrm{~V} / \mathrm{m}$.

\subsection{SERS Measurements}

The obtained fiber probes were dipped into $\mathrm{CV}$ or R6G solutions with different concentrations $\left(10^{-3}, 10^{-4}, 10^{-5}, 10^{-6}, 10^{-7}, 10^{-8}\right.$, and $10^{-9} \mathrm{M}$, respectively) for $5 \mathrm{~h}$ for further Raman measurement. The SERS performance was characterized by Raman scattering spectra (LABHRev-UV, Horiba, Japan), under $633 \mathrm{~nm}$ laser excitation. The laser power was $10.6 \mathrm{~mW}$. The accumulation and integration durations were $3 \mathrm{~s}$ and $4 \mathrm{~s}$, respectively. The laser beam was focused on the fiber core center surface through a $50 \times$ objective lens, 
and the beam size was approximately $2 \mu \mathrm{m}$. The laser beam propagated through fiber, reached the nanostructure coated end-tip, interacted with analyte molecules and Au-Ag nanostructures. The scattering signal transmitted backward within the fiber and received by the detector follows the setup diagram shown in Figure S3.

\section{Results}

\subsection{Long Spiky Au-Ag Nanostars}

The TEM images of synthesized nanostructure morphologies (Figure 1a-d) indicated that spiky tips generated and grew with LSB concentrations increase. Irregular nanoparticles with $\sim 30 \mathrm{~nm}$ core diameter and short blunt tips were obtained when LSB concentration was $25 \mathrm{mM}$ (Figure 1a). Spiky tips and larger core diameter $(\sim 40 \mathrm{~nm})$ nanostructures were obtained when LSB concentration was $50 \mathrm{mM}$ (Figure 1b). Larger core diameters and longer spiky tips nanostructures were obtained with further LSB concentration increase (Figure 1c,d). Linear LSB molecular structure includes hydrophilic group at one end, and hydrophobic group at another end, which can be assembled into spherical micelles acted as soft templated for spiky nanostructure formation and growth [42]. Considering small particles may provide denser LSPR hot-spot and the difficulty of fiber assembling, spiky nanostructures synthesized with $50 \mathrm{mM}$ LSB were chosen for further fiber probe fabrication and SERS performance investigation. The UV-Vis-NIR spectra (Figure 1e) were consistent with the morphologies of obtained nanostructures. The nanostar synthesized using $25 \mathrm{mM}$ LSB had two main peaks. The peak centered at $550 \mathrm{~nm}$ mainly came from the sphere-like core, which was close to the spherical FDTD simulated extinction peak [43] and plasmonic band of spherical gold nanoparticles [44]. The peak centered at $675 \mathrm{~nm}$ was derived from the short blunt tips plasmonic band. In fact, the peaks red-shifted with LSB concentration increase, and the sphere-like plasmonic peaks weakened and disappeared, which indicated the formation of long spiky brunches on the larger core. In addition, the extinction peaks from the spiky nanostars synthesized using 50,75, and $100 \mathrm{mM}$ LSB were similar with those simulated and experimental extinction peaks $[43,45]$ due to similar sizes and geometries. The strong infrared absorption originated from multiple plasmon modes or the longitude propagations mode along with tips, similar to gold nanorod infrared absorption [46]. Moreover, broad peaks indicated the irregular geometries of synthesized nanostructures. The strong infrared absorption also indicated potential infrared SERS applications.
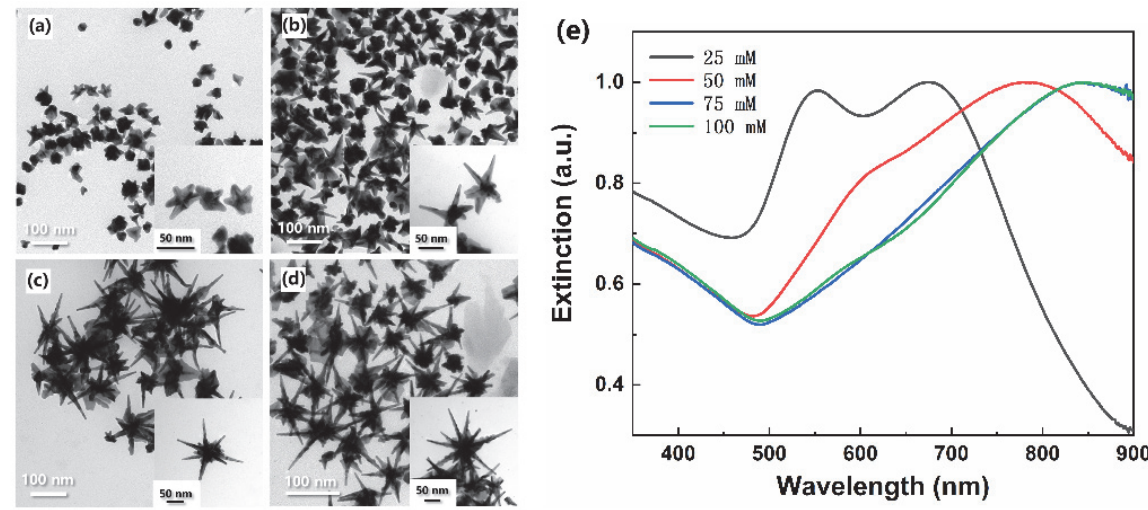

Figure 1. TEM images of nanostructures synthesized with different LSB concentrations: $25 \mathrm{mM}$ (a), $50 \mathrm{mM}$ (b), $75 \mathrm{mM}$ (c), and $100 \mathrm{mM}(\mathbf{d})$, inset images were detailed nanostructures geometries of independent particles, and (e) extinction spectra of the nanostructures.

To confirm the components and element distributions of the obtained nanostructures, the crystal phase structure was investigated by XRD pattern (Figure 2a), high-resolution TEM (Figure 2b,c), EDS analysis (Figure S4), and selected area mapping (Figure 3). The diffraction peaks were assigned to the (1 1 1 1), (2 00 ), (2 20 ), (3 1 1), and (2 2 2 $)$ crystal planes of the face-centered cubic Au [JCPDS 04-0784] and Ag [JCPDS 04-0783] with nearly the same 
standard patterns. The selected area electron diffraction (SAED) image (Figure 2b inset) also indicated the crystal planes of gold and silver. In addition, the facet had lattice fringes with interplanar space of $0.231 \mathrm{~nm}$, corresponding to the $\left(\begin{array}{lll}1 & 1 & 1\end{array}\right)$ planes of a faced-centered cubic Au-Ag alloy structure [47,48]. These confirmed the nanostructure constitution of gold and silver. Moreover, the EDS spectrum furtherly confirmed the compositions of silver and gold in nanostructures (Figure S4), and Au-Ag alloy long spiky nanostructure (Figure 3a). The Au and Ag distribution was furtherly analyzed using EDS line scan and area mapping. The whole spiky nanostructure mapping furtherly confirmed the components of Au and Ag (Figure 3a-c). In addition, the line scanning from top spiky branch to bottom showed different $\mathrm{Au} / \mathrm{Ag}$ molar ratios. Ag concentrations were gradually decreased from brunch top to bottom, while Au increased for both lines 1, and 2 (Figure 3a,d,e). Moreover, the area scanning results showed different Au-Ag concentration distributions at different nanostructure positions (Figure 3a, Table S1). The Au/Ag elements distributions were determined by the nanostructure formation and growth process, which from the inhibiting effect of reduced $\mathrm{Ag}$ on $\mathrm{Au}$ nanoparticles. In detail, $\mathrm{Au}^{3+}$ ions were firstly reduced by ascorbic acid, and Au nanoparticles were formed due to higher reduction potential than that of $\mathrm{Ag}^{+}$ions [48]. Then, reduced $\mathrm{Ag}$ clusters were gradually formed and attached to $\mathrm{Au}$ nanoparticles, which impeded the further growth of $\mathrm{Au}$ nanoparticles. The $\mathrm{Au}$ nanoparticles could furtherly grow from the active sites, resulting in the formation of multibranched star shape and inhomogeneous element distributions. Moreover, long spiky nanostars formation was due to linear LSB molecular as nanostructure growth skeleton. Higher Ag content at spiky brunch top potentially resulted in stronger LSPR electric field intensity and better SERS performance.

The electromagnetic field distribution of synthesized long spiky nanostars under $633 \mathrm{~nm}$ laser excitation was simulated using finite difference time domain (FDTD) analysis. The 3D model was constructed following the TEM image (Figure 1b), with a $40 \mathrm{~nm}$ core diameter and $100 \mathrm{~nm}$ spiky brunch length, and individual, colliding tip-top, top, and intersecting forms (Figure S2). The laser-induced electric field was along with the $x$-axis. The results indicated that the strongest electric field was at the closed corner of the nanostars due to the nano-gap effect [49] In addition, an intense electric field also was found at the toptip of the brunch (Figure 4a). For colliding tip-top nanostars, the maximum electric intensity could reach $38.8 \mathrm{~V} / \mathrm{m}$, at closed brunch tips gap and nanostar corners (Figure $4 \mathrm{~b}$ ). Moreover, a strong electric field was found at the space of the vertex angles of the two nanostars (Figure 4c), as well as the nanostar corners. The strong electric field intensity and larger distribution area indicated intense and more LSPR hot-spot for better SERS performance.
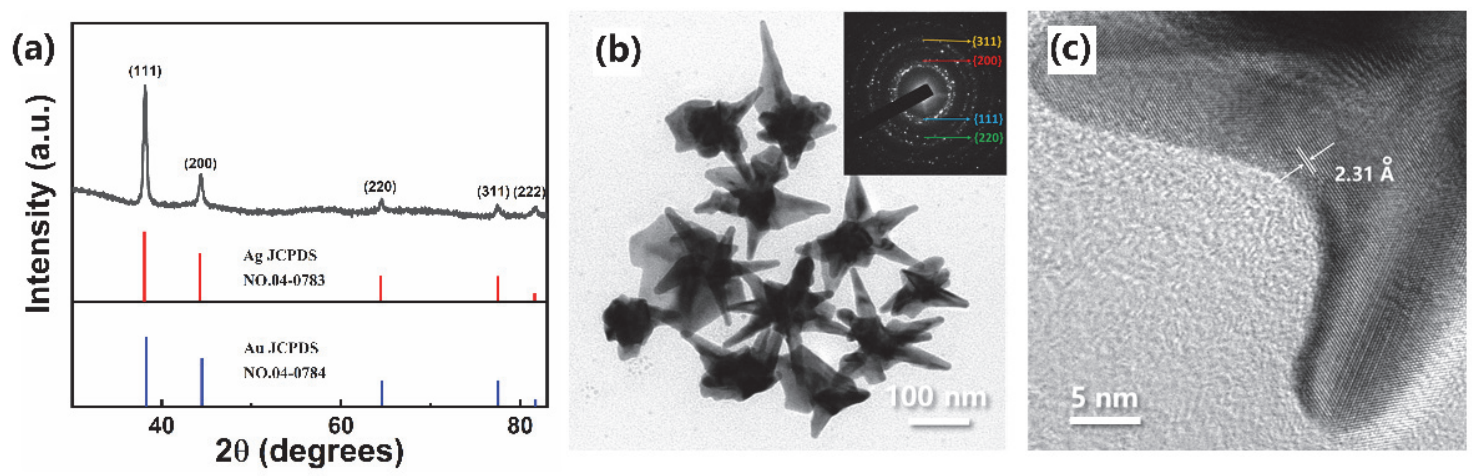

Figure 2. The XRD pattern (a), TEM image (b), inset was Fourier electron diffraction image, HR-TEM image (c), and Au-Ag nanostars synthesized with $50 \mathrm{mM} \mathrm{LSB}$. 

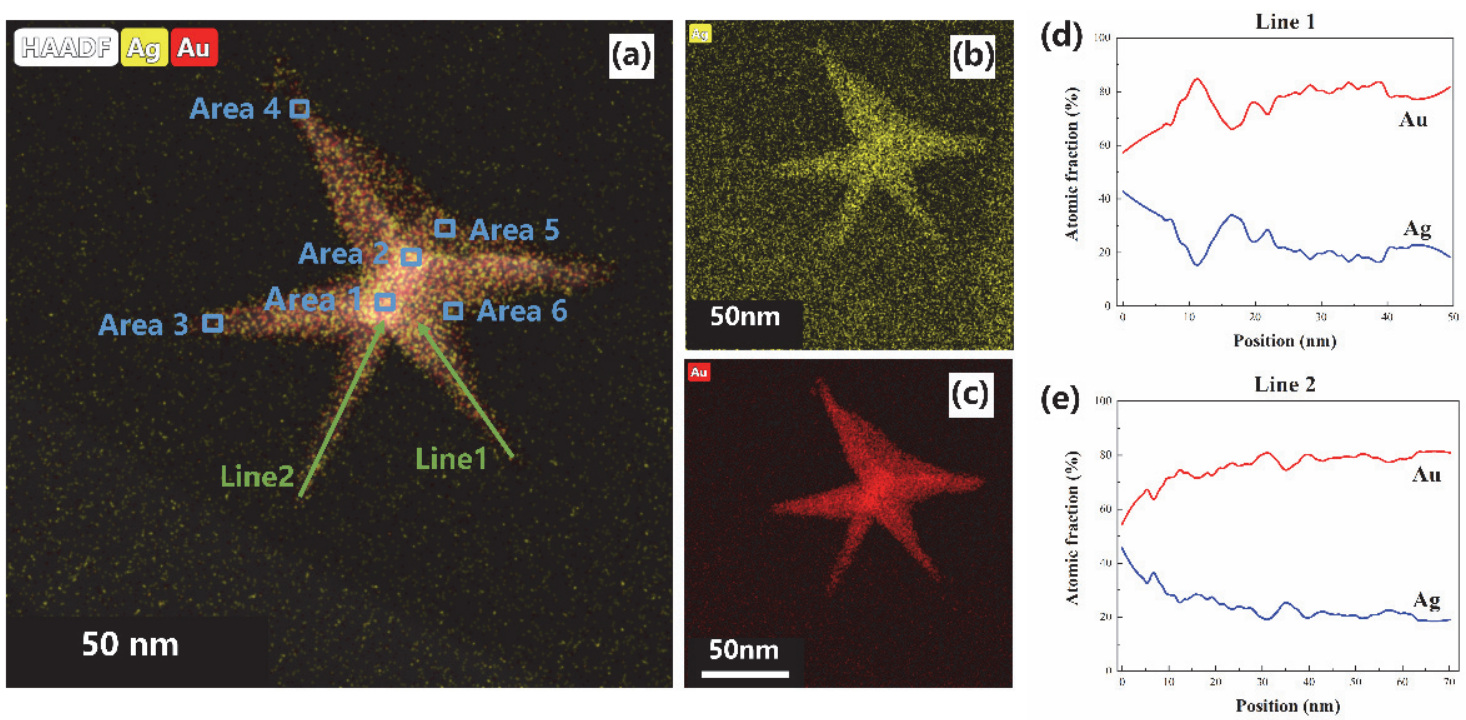

Figure 3. Au and Ag elements distributions of long spiky nanostar (a), separated Au (b) and Ag (c) distribution, and line scanning distribution of the brunch tips line 1 (d) and line 2 (e). The lines were smoothed.

(a)

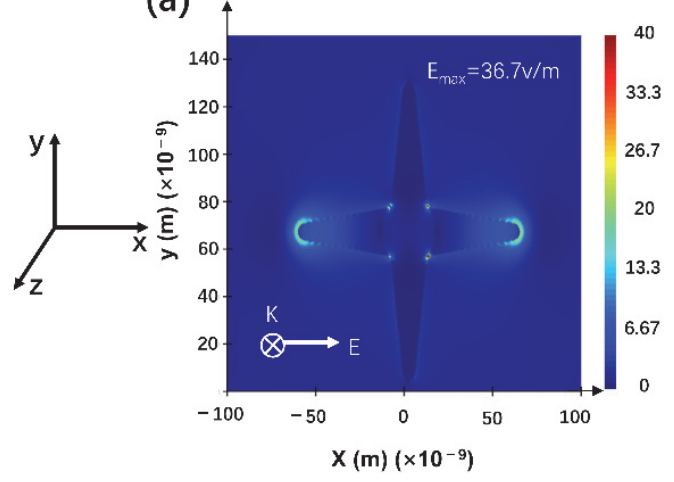

(b)

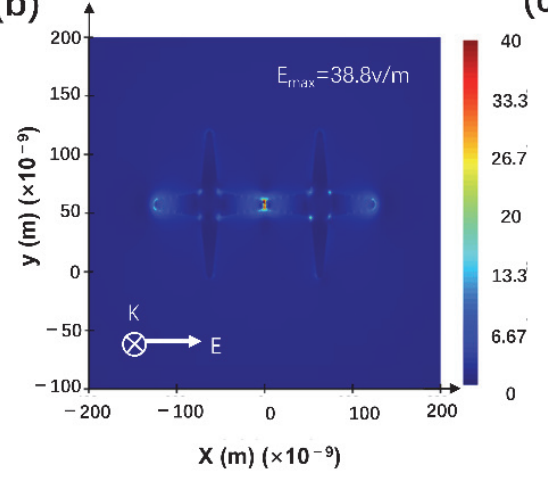

(c)

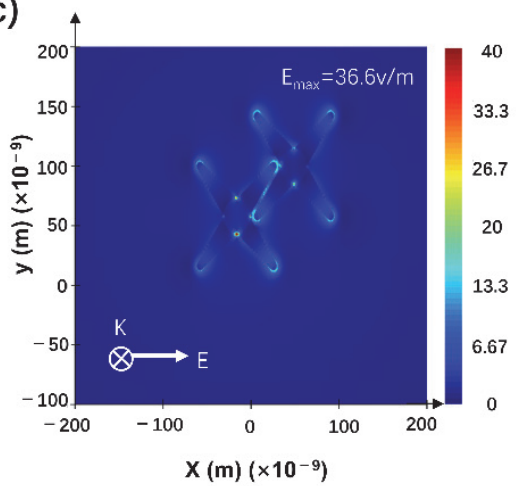

Figure 4. Simulated electric distribution from single nanostar (a) colliding tip-top nanostars (b) and intercrossed (c) long spiky Au-Ag nanostars.

\subsection{SERS Performance of Fiber Probes}

The optical microscope images of uncoated fiber showed transparency (Figure S5a) and smooth terminal end surface (Figure S5b), while being dark for Au-Ag spiky nanostructures coated fiber (Figure 5a) from the scattering and absorption from nanostructures, which indicated the presence of nanostructures on the fiber walls. Furthermore, SEM images showed the nanostructures homogeneously and densely coated on the fiber end facet (Figure $5 b, c$ ) by surface silanization and electrostatic adsorption. The Raman peaks at $1619 \mathrm{~cm}^{-1}$ intensities distributions using $10^{-4} \mathrm{M} \mathrm{CV}$ as analyte on the fiber end facet showed a Gaussian-like change from the center to the edge in the fiber core (Figure 6a), which was similar with the intensities from blank fiber using $0.1 \mathrm{M} \mathrm{CV}$ as analyte (Figure $6 \mathrm{~b}$ ). Therefore, fiber core centers were chosen for following Raman performance characterization as focused incident beam input positions. 


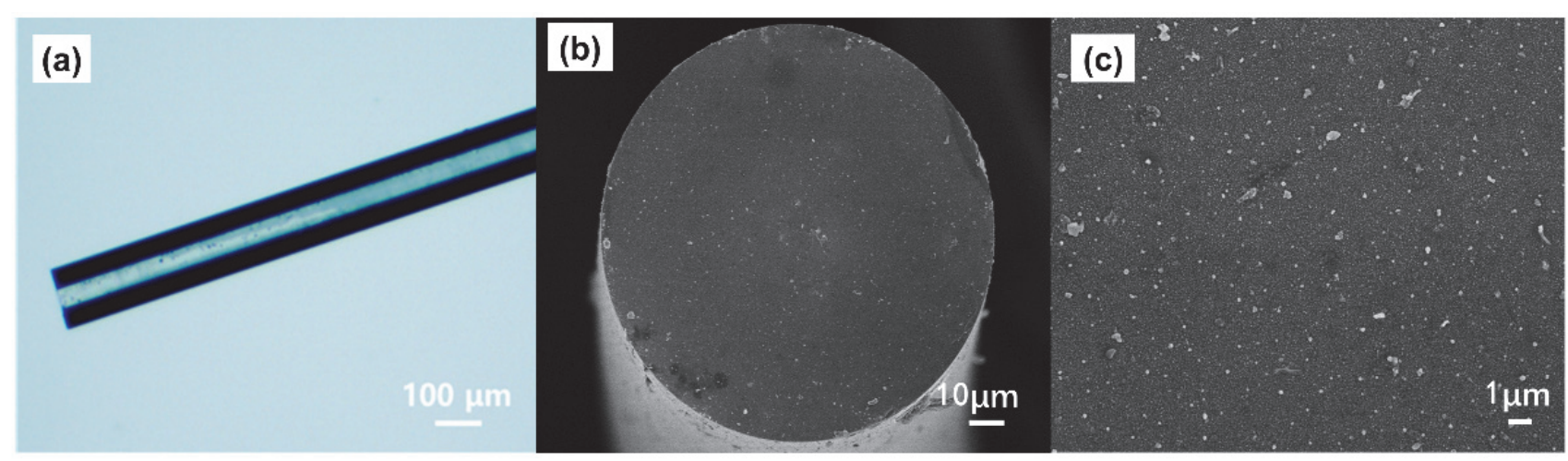

Figure 5. The digital image of SERS fiber probe (a), and SEM image of SERS probe with Au-Ag alloy. Nanostars on the terminal end (b). The amplification image (c).

(a)

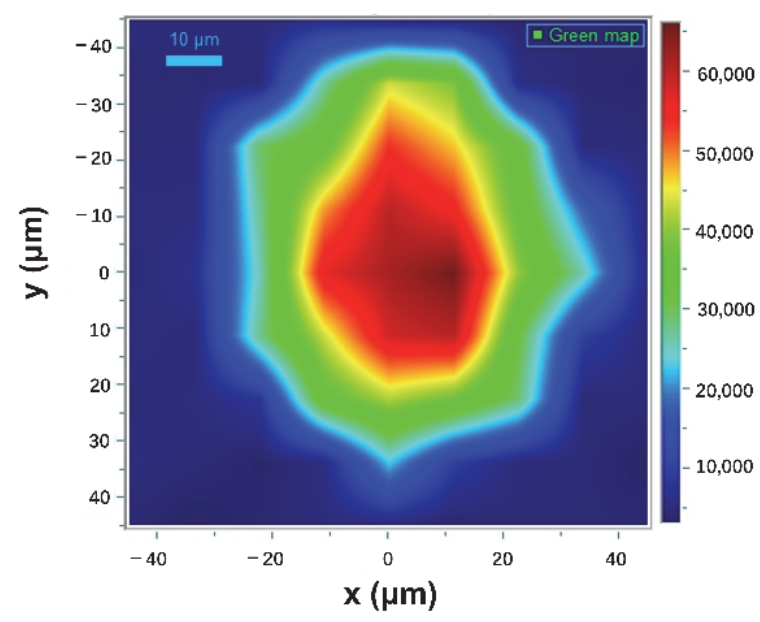

(b)

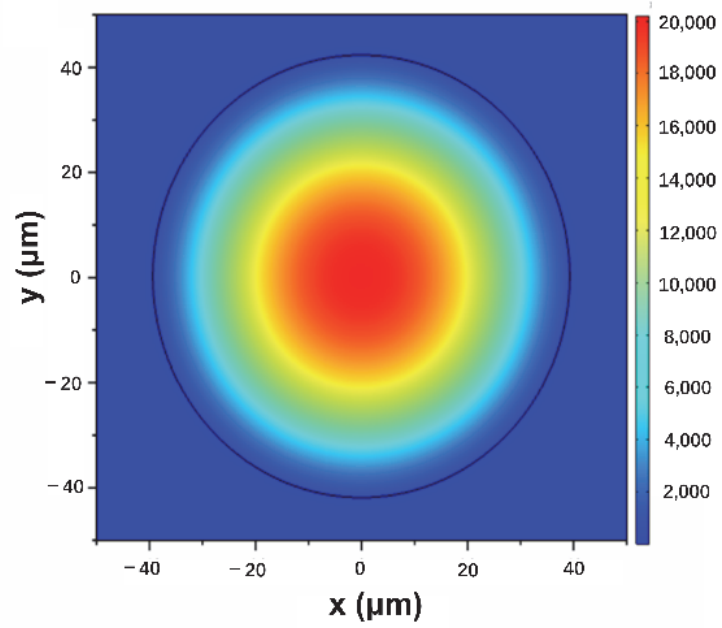

Figure 6. Raman intensities distribution mapping of SERS fiber probe terminal end (a) and Raman intensities distribution mapping of blank fiber terminal end (b).

The SERS behaviors of fabricated fiber probes were characterized using CV and R6G as analyte molecules, with different concentrations ranging from $10^{-4}$ to $10^{-9} \mathrm{M}$. The Raman spectra of CV (Figure 7a) showed that the five main peaks centered at 920, 1171, 1305,1390 , and $1619 \mathrm{~cm}^{-1}$ could be assigned to out-of-plane vibration of ring $\mathrm{C}-\mathrm{H}$, ring skeletal vibration of radical orientation, in-plane vibration of ring $\mathrm{C}-\mathrm{H}, \mathrm{N}$-phenyl stretching vibration, and ring C-C stretching vibration, respectively, from the CV molecules [50]. The Raman intensities decreased with a decrease in the concentration until the CV concentration was $10^{-9} \mathrm{M}$. The lowest detectable concentration or detection limit could be as low as $10^{-8} \mathrm{M}$ for long spiky Au-Ag nanostar-based fiber probe, following the signal and noise ratio larger than three standards. This detection limit was similar or lower than that of recently reported fiber probes [51-53]. There were no obvious Raman peaks found with $10^{-3}$ M CV using glass fiber directly (Figure 7a). The relationship between CV molecule concentrations and Raman intensities at $1619 \mathrm{~cm}^{-1}$ was linear (Figure $7 \mathrm{~b}$ ), which indicated promising potential quantitative analysis using these fiber probes. The Raman spectra of R6G showed six main peaks (Figure 7c) centered at 1651, 1509, 1361, 1310,1187, and $774 \mathrm{~cm}^{-1}$ which could be assigned to ring C-C stretching, N-H bending vibration, and outof-plane vibration of ring $\mathrm{C}-\mathrm{H}$, respectively, from R6G molecules [54]. The $10^{-8} \mathrm{M}$ lowest detectable limit and the linear R6G concentrations and Raman intensities at $1361 \mathrm{~cm}^{-1}$ (Figure 7d) indicated highly sensitive fiber probes for both qualitative and quantitative molecules detection. 

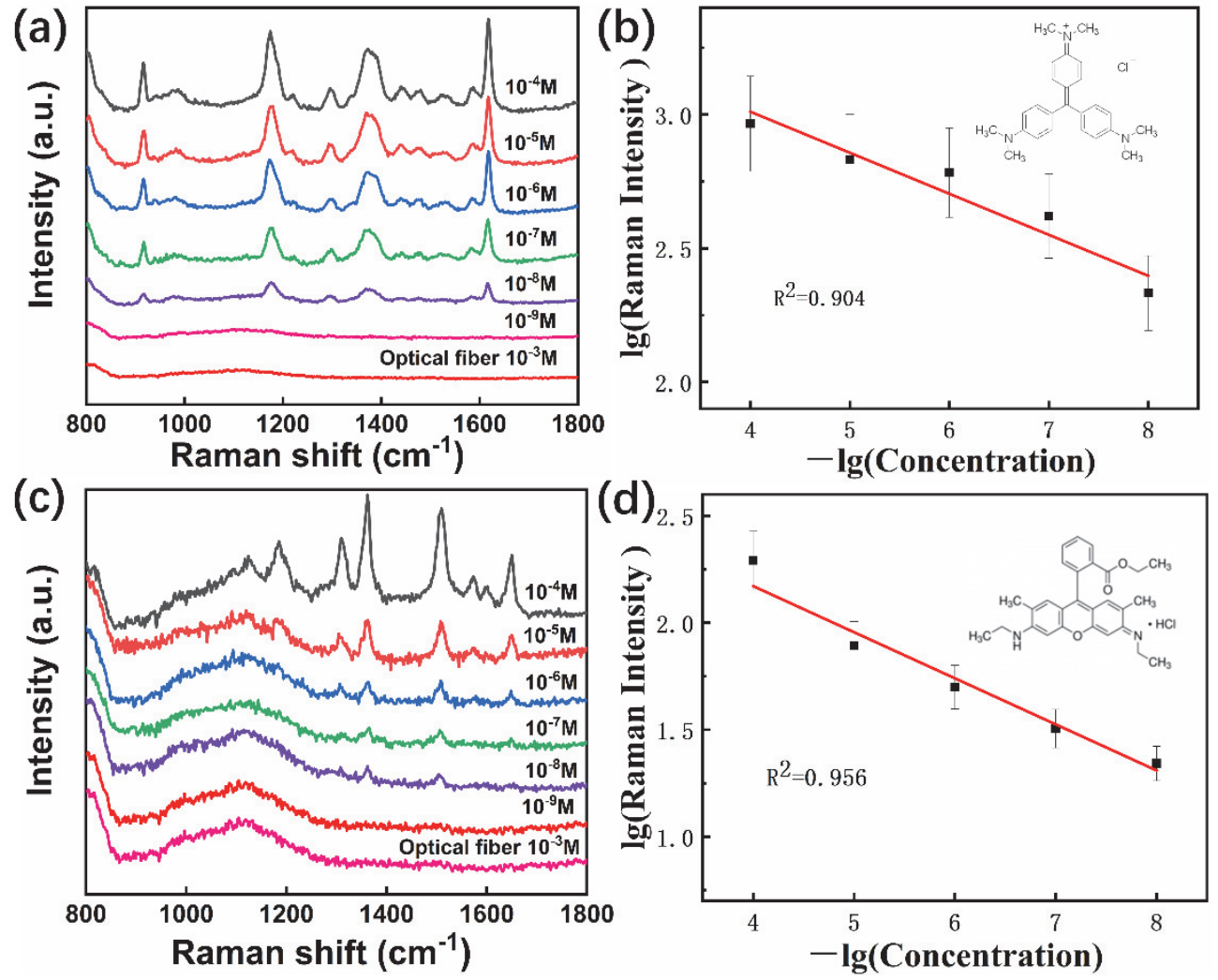

Figure 7. Raman spectra of CV molecules with concentrations from $10^{-4} \mathrm{M}$ to $10^{-9} \mathrm{M}$, using SERS fiber probes, under $633 \mathrm{~nm}$ laser excitation (a), and the relationship between CV concentrations and $1619 \mathrm{~cm}^{-1}$ peak intensities (b), Raman spectra of R6G molecules with concentration from $10^{-4}$ to $10^{-9} \mathrm{M}(\mathrm{c})$, and the relationship between R6G concentrations and 1361 peak intensities (d). The optical fiber in $(\mathbf{a}, \mathbf{c})$ indicated Raman spectrum of $10^{-3} \mathrm{M} \mathrm{CV}$ or R6G using naked fiber.

The enhancement factor (EF) of fiber probe could be calculated using Equation (1) from Gupta [55].

$$
\mathrm{EF}=\left(\mathrm{I}_{\mathrm{SERS}} / \mathrm{N}_{\mathrm{SERS}}\right) /\left(\mathrm{I}_{\text {neat }} / \mathrm{N}_{\text {neat }}\right)
$$

Here, ISERS and $I_{\text {neat }}$ represent Raman signal intensities from SERS fiber probe and silica fiber, and $\mathrm{N}_{\text {SERS, }}$ and $\mathrm{N}_{\text {neat }}$ are the molecules numbers involved in Raman signal generation from SERS fiber probe and silica fiber. The Raman intensities could be obtained from Raman spectra of $1.0 \times 10^{-8} \mathrm{M} \mathrm{CV}$ using an SERS fiber probe and $0.1 \mathrm{M} \mathrm{CV}$ using silica fiber (Figure S6). The I SERS and I neat were evaluated following the detailed processes provided by Liu et al. [56], with single-layer molecules assumption. The calculated EF was $6.23 \times 10^{6}$, using CV analyte. Detailed calculation process is provided in the Supporting Information section.

The reproducibility of SERS fiber probes was characterized by the comparison of the intensities of Raman peaks from the same batch fiber probes fabricated with identical parameters using $10^{-5} \mathrm{M} \mathrm{CV}$ as an analyte. All of the Raman peaks could be assigned to different vibrations from $\mathrm{CV}$ and showed similar intensities (Figure 8a). The intensities of $1619 \mathrm{~cm}^{-1}$ peaks were around 690 , albeit with a small difference. The related standard deviation was $4.93 \%$ for $10^{-5} \mathrm{CV}$, which indicated high reproducibility of the fabricated fiber probes and potential large-scale analysis applications. 
(a)

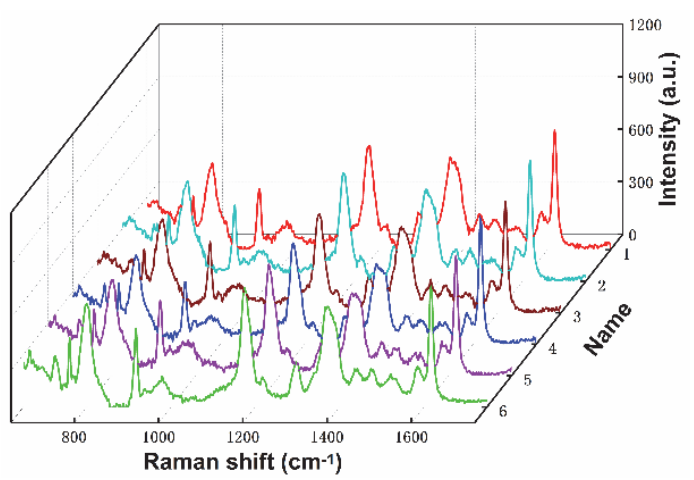

(b)

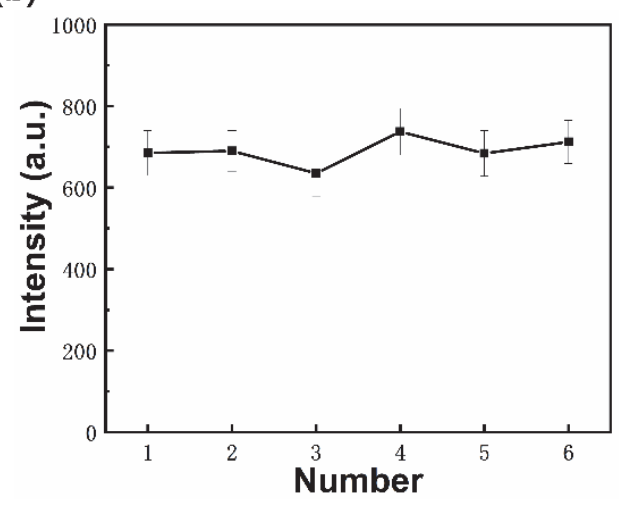

Figure 8. Raman spectra of $10^{-5} \mathrm{CV}$ molecules (a) and $1619 \mathrm{~cm}^{-1}$ peak intensities (b) using same batch fiber probes.

The stability of the fiber probes was characterized by exposed fiber probes in the air for 30 days at $25^{\circ} \mathrm{C}$ and measured Raman spectra using $10^{-6} \mathrm{M} \mathrm{CV}$ every 10 days with the same parameters. The Raman peak intensities decreased with extended exposure durations (Figure 9a). The $1619 \mathrm{~cm}^{-1}$ peak intensities decreased from 210 to 160 , or around 20\% (Figure $9 \mathrm{~b}$ ). The fiber probes showed better stability than other silver nanostructure-based probes [57] for both the Au component and the special structure.

(a)

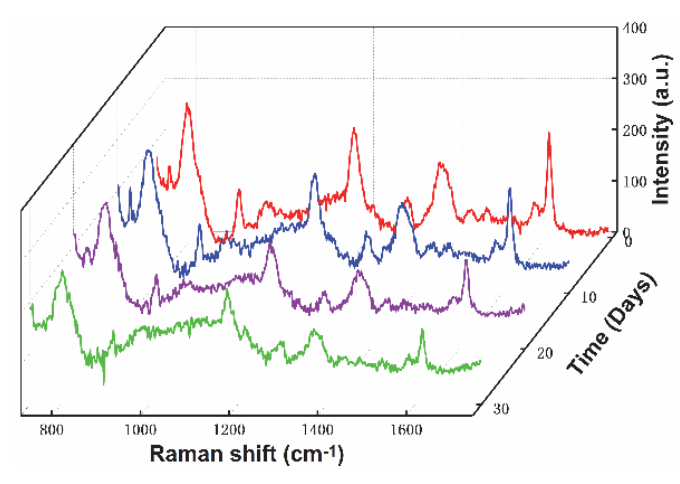

(b)

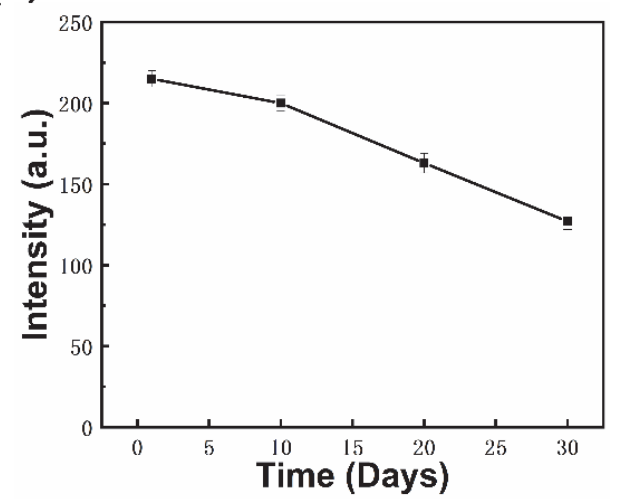

Figure 9. Raman spectra of $10^{-6} \mathrm{M} \mathrm{CV}$ molecules (a) and $1619 \mathrm{~cm}^{-1}$ peak intensities (b) using fiber probe exposed in air for different durations.

\section{Conclusions}

In conclusion, long spiky Au-Ag alloy nanostar-based fiber probes were fabricated, and SERS performances of the fiber probes were investigated in this paper. The nanostars were synthesized using the metal ions reduction method. The geometries, core sizes, and brunch tip length were controlled by LSB concentrations (as the nanostructure growth skeleton). $\mathrm{The} \mathrm{Au}$, and $\mathrm{Ag}$ element distributions in long spiky nanostars were inhomogeneous and there was a higher Ag content at the brunch tip top. The fiber probes were fabricated by fiber silanization and electrostatic adsorption. The detection limit of the fiber probes could reach $10^{-8} \mathrm{M}$ for both CV and R6G molecules. The enhancement factor could be $6.23 \times 10^{6}$ using $\mathrm{CV}$ as analyte. The relationship between analyte concentrations and Raman intensities was linear, which is beneficial for potential quantitative analysis. Moreover, the $4.93 \%$ related standard deviation for the same batch fiber probes indicated good reproducibility, and 20\% Raman signal decay for 30-day exposure in air showed good stability of the fiber probes. The long spiky Au-Ag alloy nanostar-based fiber probes could be applied in low concentration substance detection. 
Supplementary Materials: The following supporting information can be downloaded at: https: / / www.mdpi.com/article/10.3390/ma15041498/s1. Figure S1. The diagram of SERS fiber probe fabrication. Figure S2. The 3D model of individual Au-Ag nanostar (a), colliding tip top nanostars (b), and two intertwined nanostars (c), Figure S3. The diagram of Raman measurement setup for SERS optical fiber probes, Figure S4. EDS spectrum of synthesized Au-Ag nanostars. The carbon, copper, and molybdenum were from copper mesh, carbon film and molybdenum ring for measurement. Table S1. The concentration of Au and Ag at different parts of nanostar in Figure 3a, Figure S5. The digital image of side view of silica fiber (a) and SEM image of fiber terminal facet (b), Figure S6. Raman spectrum of 10-8 M CV measured with SERS probe of long spiky Au-Ag alloy nanostars (a), Raman spectrum of $1.0 \mathrm{M} \mathrm{CV}$ measured with common multimode fiber (b). The peak centered at $1619 \mathrm{~cm}-1$ was selected for EF calculation.

Author Contributions: Methodology, data curation, writing original draft, writing-review and editing, G.H.; methodology, data curation, investigation, X.H.; data curation, investigation, S.C. and K.C.; investigation, supervision, Q.T.; conceptualization, methodology, project administration, writing-review \& editing, supervision, J.Z. All authors have read and agreed to the published version of the manuscript.

Funding: This research received no external funding.

Institutional Review Board Statement: Not applicable.

Informed Consent Statement: Not applicable.

Data Availability Statement: Not applicable.

Acknowledgments: This research was financially supported by the opening funding of the state key laboratory of silicate materials for architecture (SYSJJ2018-06) and the Fundamental Research Funds for the Central Universities (WUT: 2016VA096), China. The author Jihong Zhang would like to thank Utada Hikaru, for her beautiful songs inspired this research.

Conflicts of Interest: The authors declare no conflict of interest.

\section{References}

1. Jeong, Y.; Kook, Y.-M.; Lee, K.; Koh, W.-G. Metal enhanced fluorescence (MEF) for biosensors: General approaches and a review of recent developments. Biosens. Bioelectron. 2018, 111, 102-116. [CrossRef] [PubMed]

2. $\quad$ Li, C.; Huang, Y.; Li, X.; Zhang, Y.; Chen, Q.; Ye, Z.; Alqarni, Z.; Bell, S.E.J.; Xu, Y. Towards practical and sustainable SERS: A review of recent developments in the construction of multifunctional enhancing substrates. J. Mater. Chem. C 2021, 9, 11517-11552. [CrossRef]

3. Tim, B.; Błaszkiewicz, P.; Kotkowiak, M. Recent advances in metallic nanoparticle assemblies for surface-enhanced spectroscopy. Int. J. Mol. Sci. 2022, 23, 291. [CrossRef] [PubMed]

4. Li, J.J.; Wu, C.; Zhao, J.; Weng, G.J.; Zhu, J.; Zhao, J.W. Synthesis and SERS activity of super-multibranched AuAg nanostructure via silver coating-induced aggregation of nanostars. Spectrochim. Acta A Mol. Biomol. Spectrosc. 2018, 204, 380-387. [CrossRef] [PubMed]

5. Jiang, N.; Zhuo, X.; Wang, J. Active Plasmonics: Principles, Structures, and Applications. Chem. Rev. 2018, 118, 3054-3099. [CrossRef] [PubMed]

6. Unser, S.; Bruzas, I.; He, J.; Sagle, L. Localized Surface Plasmon Resonance Biosensing: Current Challenges and Approaches. Sensors 2015, 15, 15684-15716. [CrossRef]

7. Liu, Y.; Yuan, H.; Fales, A.M.; Vo-Dinh, T. pH-sensing nanostar probe using surface-enhanced Raman scattering (SERS): Theoretical and experimental studies. J. Raman Spectrosc. 2013, 44, 980-986. [CrossRef]

8. Guselnikova, O.; Postnikov, P.; Erzina, M.; Kalachyova, Y.; Švorčík, V.; Lyutakov, O. Pretreatment-free selective and reproducible SERS-based detection of heavy metal ions on DTPA functionalized plasmonic platform. Sens. Actuators B Chem. 2017, 253, 830-838. [CrossRef]

9. Senthil Kumar, P.; Pastoriza-Santos, I.; Rodriguez-Gonzalez, B.; Javier Garcia de Abajo, F.; Liz-Marzan, L.M. High-yield synthesis and optical response of gold nanostars. Nanotechnology 2008, 19, 015606. [CrossRef]

10. Schutz, M.; Steinigeweg, D.; Salehi, M.; Kompe, K.; Schlucker, S. Hydrophilically stabilized gold nanostars as SERS labels for tissue imaging of the tumor suppressor p63 by immuno-SERS microscopy. Chem. Commun. (Camb.) 2011, 47, 4216-4218. [CrossRef]

11. Fales, A.M.; Yuan, H.; Vo-Dinh, T. Cell-penetrating peptide enhanced intracellular Raman imaging and photodynamic therapy. Mol. Pharm. 2013, 10, 2291-2298. [CrossRef] [PubMed]

12. Liu, Z.; Yan, Z.; Bai, L. Layer-by-layer assembly of polyelectrolyte and gold nanoparticle for highly reproducible and stable SERS substrate. Appl. Surf. Sci. 2016, 360, 437-441. [CrossRef] 
13. Aroca, R.F.; Goulet, P.J.; dos Santos, D.S., Jr.; Alvarez-Puebla, R.A.; Oliveira, O.N., Jr. Silver nanowire layer-by-layer films as substrates for surface-enhanced Raman scattering. Anal. Chem. 2005, 77, 378-382. [CrossRef] [PubMed]

14. Su, Y.; Xu, S.; Zhang, J.; Chen, X.; Jiang, L.P.; Zheng, T.; Zhu, J.J. Plasmon Near-Field Coupling of Bimetallic Nanostars and a Hierarchical Bimetallic SERS "Hot Field": Toward Ultrasensitive Simultaneous Detection of Multiple Cardiorenal Syndrome Biomarkers. Anal. Chem. 2019, 91, 864-872. [CrossRef]

15. Zhang, T.; Sun, Y.; Hang, L.; Li, H.; Liu, G.; Zhang, X.; Lyu, X.; Cai, W.; Li, Y. Periodic Porous Alloyed Au-Ag Nanosphere Arrays and Their Highly Sensitive SERS Performance with Good Reproducibility and High Density of Hotspots. ACS Appl. Mater. Interfaces 2018, 10, 9792-9801. [CrossRef]

16. Shen, J.; Zhang, L.; Liu, L.; Wang, B.; Bai, J.; Shen, C.; Chen, Y.; Fan, Q.; Chen, S.; Wu, W.; et al. Revealing Lectin-Sugar Interactions with a Single Au@Ag Nanocube. ACS Appl. Mater. Interfaces 2019, 11, 40944-40950. [CrossRef]

17. Waiwijit, U.; Chananonnawathorn, C.; Eimchai, P.; Bora, T.; Hornyak, G.L.; Nuntawong, N. Fabrication of Au-Ag nanorod SERS substrates by co-sputtering technique and dealloying with selective chemical etching. Appl. Surf. Sci. 2020, 530, 147171. [CrossRef]

18. Liu, Y.; Pan, M.; Wang, W.; Jiang, Q.; Wang, F.; Pang, D.W.; Liu, X. Plasmonic and Photothermal Immunoassay via EnzymeTriggered Crystal Growth on Gold Nanostars. Anal. Chem. 2019, 91, 2086-2092. [CrossRef]

19. Li, D.; Yang, M.; Li, H.; Mao, L.; Wang, Y.; Sun, B. SERS based protocol using flow glass-hemostix for detection of neuron-specific enolase in blood plasma. New J. Chem. 2019, 43, 5925-5931. [CrossRef]

20. Kong, K.V.; Ho, C.J.; Gong, T.; Lau, W.K.; Olivo, M. Sensitive SERS glucose sensing in biological media using alkyne functionalized boronic acid on planar substrates. Biosens. Bioelectron. 2014, 56, 186-191. [CrossRef]

21. Zhou, H.; Yang, D.; Ivleva, N.P.; Mircescu, N.E.; Niessner, R.; Haisch, C. SERS detection of bacteria in water by in situ coating with Ag nanoparticles. Anal. Chem. 2014, 86, 1525-1533. [CrossRef] [PubMed]

22. Yang, Y.; Zhang, Q.; Fu, Z.W.; Qin, D. Transformation of Ag nanocubes into Ag-Au hollow nanostructures with enriched Ag contents to improve SERS activity and chemical stability. ACS Appl. Mater. Interfaces 2014, 6, 3750-3757. [CrossRef] [PubMed]

23. Deiss, F.; Sojic, N.; White, D.J.; Stoddart, P.R. Nanostructured optical fibre arrays for high-density biochemical sensing and remote imaging. Anal. Bioanal. Chem. 2010, 396, 53-71. [CrossRef] [PubMed]

24. Schlucker, S. Surface-enhanced Raman spectroscopy: Concepts and chemical applications. Angew. Chem. Int. Ed. Engl. 2014, 53, 4756-4795. [CrossRef]

25. Ma, L.; Huang, Y.; Hou, M.; Xie, Z.; Zhang, Z. Silver Nanorods Wrapped with Ultrathin $\mathrm{Al}_{2} \mathrm{O}_{3}$ Layers Exhibiting Excellent SERS Sensitivity and Outstanding SERS Stability. Sci. Rep. 2015, 5, 12890. [CrossRef]

26. Kou, X.; Ni, W.; Tsung, C.K.; Chan, K.; Lin, H.Q.; Stucky, G.D.; Wang, J. Growth of gold bipyramids with improved yield and their curvature-directed oxidation. Small 2007, 3, 2103-2113. [CrossRef]

27. Gilroy, K.D.; Ruditskiy, A.; Peng, H.C.; Qin, D.; Xia, Y. Bimetallic Nanocrystals: Syntheses, Properties, and Applications. Chem. Rev. 2016, 116, 10414-10472. [CrossRef]

28. Lee, T.; Kwon, S.; Lee, J.-J. Highly Dense and Accessible Nanogaps in Au-Ag Alloy Patterned Nanostructures for SurfaceEnhanced Raman Spectroscopy Analysis. ACS Appl. Nano Mater. 2020, 3, 5920-5927. [CrossRef]

29. Zaleska-Medynska, A.; Marchelek, M.; Diak, M.; Grabowska, E. Noble metal-based bimetallic nanoparticles: The effect of the structure on the optical, catalytic and photocatalytic properties. Adv. Colloid. Interface Sci. 2016, 229, 80-107. [CrossRef]

30. Ran, Y.; Strobbia, P.; Cupil-Garcia, V.; Vo-Dinh, T. Fiber-optrode SERS probes using plasmonic silver-coated gold nanostars. Sens. Actuators B Chem. 2019, 287, 95-101. [CrossRef]

31. He, S.; Chua, J.; Tan, E.K.M.; Kah, J.C.Y. Optimizing the SERS enhancement of a facile gold nanostar immobilized paper-based SERS substrate. RSC Adv. 2017, 7, 16264-16272. [CrossRef]

32. Pham, T.B.; Hoang, T.H.C.; Pham, V.H.; Nguyen, V.C.; Nguyen, T.V.; Vu, D.C.; Pham, V.H.; Bui, H. Detection of Permethrin pesticide using silver nano-dendrites SERS on optical fibre fabricated by laser-assisted photochemical method. Sci. Rep. 2019, 9, 12590. [CrossRef] [PubMed]

33. Li, J.; Wang, H.; Li, Z.; Su, Z.; Zhu, Y. Preparation and Application of Metal Nanoparticals Elaborated Fiber Sensors. Sensors 2020, 20, 5155. [CrossRef] [PubMed]

34. Long, Y.; Li, H.; Yang, X.; Yuan, Y.; Zheng, M. Controlling silver morphology on a cramped optical fiber facet via a PVP-assisted silver mirror reaction for SERS fiber probe fabrication. New J. Chem. 2021, 45, 4004-4015. [CrossRef]

35. Li, L.; Deng, S.; Wang, H.; Zhang, R.; Zhu, K.; Lu, Y.; Wang, Z.; Zong, S.; Wang, Z.; Cui, Y. A SERS fiber probe fabricated by layer-by-layer assembly of silver sphere nanoparticles and nanorods with a greatly enhanced sensitivity for remote sensing. Nanotechnology 2019, 30, 255503. [CrossRef]

36. Ma, W.; Sun, M.; Xu, L.; Wang, L.; Kuang, H.; Xu, C. A SERS active gold nanostar dimer for mercury ion detection. Chem. Commun. (Camb.) 2013, 49, 4989-4991. [CrossRef]

37. Lin, L.-K.; Stanciu, L.A. Bisphenol A detection using gold nanostars in a SERS improved lateral flow immunochromatographic assay. Sens. Actuators B Chem. 2018, 276, 222-229. [CrossRef]

38. Bizzarri, A.R.; Cannistraro, S. SERS detection of thrombin by protein recognition using functionalized gold nanoparticles. Nanomedicine 2007, 3, 306-310. [CrossRef]

39. Krishnan, S.K.; Chipatecua Godoy, Y. Deep Eutectic Solvent-Assisted Synthesis of Au Nanostars Supported on Graphene Oxide as an Efficient Substrate for SERS-Based Molecular Sensing. ACS Omega 2020, 5, 1384-1393. [CrossRef] 
40. Chen, B.; Meng, G.; Huang, Q.; Huang, Z.; Xu, Q.; Zhu, C.; Qian, Y.; Ding, Y. Green synthesis of large-scale highly ordered core@shell nanoporous Au@Ag nanorod arrays as sensitive and reproducible 3D SERS substrates. ACS Appl. Mater. Interfaces 2014, 6, 15667-15675. [CrossRef]

41. Joseph, D.; Baskaran, R.; Yang, S.G.; Huh, Y.S.; Han, Y.K. Multifunctional spiky branched gold-silver nanostars with near-infrared and short-wavelength infrared localized surface plasmon resonances. J. Colloid. Interface Sci. 2019, 542, 308-316. [CrossRef] [PubMed]

42. Pallavicini, P.; Chirico, G.; Collini, M.; Dacarro, G.; Dona, A.; D’Alfonso, L.; Falqui, A.; Diaz-Fernandez, Y.; Freddi, S.; Garofalo, B.; et al. Synthesis of branched Au nanoparticles with tunable near-infrared LSPR using a zwitterionic surfactant. Chem. Commun. (Camb.) 2011, 47, 1315-1317. [CrossRef] [PubMed]

43. Kim, W.; Kim, N.; Park, J.W.; Kim, Z.H. Nanostar probes for tip-enhanced spectroscopy. Nanoscale 2016, 8, 987-994. [CrossRef] [PubMed]

44. Haiss, W.; Thanh, N.T.; Aveyard, J.; Fernig, D.G. Determination of size and concentration of gold nanoparticles from UV-vis spectra. Anal. Chem. 2007, 79, 4215-4221. [CrossRef] [PubMed]

45. Kumagai, K.; Ishida, A. Synthesis and Optical Properties of Flower- and Spiky-Ball-Like Silver-Gold Nanoparticles. Bull. Chem. Soc. Jpn. 2014, 87, 780-791. [CrossRef]

46. Zhuo, X.; Zhu, X.; Li, Q.; Yang, Z.; Wang, J. Gold Nanobipyramid-Directed Growth of Length-Variable Silver Nanorods with Multipolar Plasmon Resonances. ACS Nano 2015, 9, 7523-7535. [CrossRef]

47. Tian, S.; You, W.; Shen, Y.; Gu, X.; Ge, M.; Ahmadi, S.; Ahmad, S.; Kraatz, H.-B. Facile synthesis of silver-rich Au/Ag bimetallic nanoparticles with highly active SERS properties. New J. Chem. 2019, 43, 14772-14780. [CrossRef]

48. Elemike, E.E.; Onwudiwe, D.C.; Nundkumar, N.; Singh, M.; Iyekowa, O. Green synthesis of Ag, Au and Ag-Au bimetallic nanoparticles using Stigmaphyllon ovatum leaf extract and their in vitro anticancer potential. Mater. Lett. 2019, 243, 148-152. [CrossRef]

49. Zhang, L.; Liu, T.; Liu, K.; Han, L.; Yin, Y.; Gao, C. Gold Nanoframes by Nonepitaxial Growth of Au on AgI Nanocrystals for Surface-Enhanced Raman Spectroscopy. Nano Lett. 2015, 15, 4448-4454. [CrossRef]

50. Luo, X.; Liu, W.; Chen, C.; Jiang, G.; Hu, X.; Zhang, H.; Zhong, M. Femtosecond laser micro-nano structured Ag SERS substrates with unique sensitivity, uniformity and stability for food safety evaluation. Opt. Laser Technol. 2021, 139, 106969. [CrossRef]

51. Ma, H.; Cui, Q.; Xu, L.; Tian, Y.; Jiao, A.; Wang, C.; Zhang, M.; Li, S.; Chen, M. Silk fibroin fibers decorated with urchin-like Au/Ag nanoalloys: A flexible hygroscopic SERS sensor for monitoring of folic acid in human sweat. Opt. Express 2021, 29, 30892-30904. [CrossRef] [PubMed]

52. Gu, C.; Zhao, Z.; Shi, P. Development of monolayer AuNPs decorated on an optical fiber facet for SERS analysis. Appl. Opt. 2021, 60, 792-798. [CrossRef] [PubMed]

53. Mandal, P.; Tewari, B.S. Progress in surface enhanced Raman scattering molecular sensing: A review. Surf. Interfaces 2022, 28, 101655. [CrossRef]

54. Kong, X.; Squire, K.; Chong, X.; Wang, A.X. Ultra-Sensitive Lab-on-a-Chip Detection of Sudan I in Food using PlasmonicsEnhanced Diatomaceous Thin Film. Food Control 2017, 79, 258-265. [CrossRef]

55. Kleinman, S.L.; Frontiera, R.R.; Henry, A.I.; Dieringer, J.A.; Van Duyne, R.P. Creating, characterizing, and controlling chemistry with SERS hot spots. Phys. Chem. Chem. Phys. 2013, 15, 21-36. [CrossRef]

56. Liu, Z.; Yang, Z.; Peng, B.; Cao, C.; Zhang, C.; You, H.; Xiong, Q.; Li, Z.; Fang, J. Highly sensitive, uniform, and reproducible surface-enhanced Raman spectroscopy from hollow Au-Ag alloy nanourchins. Adv. Mater. 2014, 26, 2431-2439. [CrossRef]

57. Jiang, J.; Zou, S.; Ma, L.; Wang, S.; Liao, J.; Zhang, Z. Surface-Enhanced Raman Scattering Detection of Pesticide Residues Using Transparent Adhesive Tapes and Coated Silver Nanorods. ACS Appl. Mater. Interfaces 2018, 10, 9129-9135. [CrossRef] 